\title{
MENINGOENCEFALITE NECROSANTE EM BOVINOS CAUSADA POR HERPESVÍRUS BOVINO NO ESTADO DE MATO GROSSO, BRASIL ${ }^{1}$
}

\author{
NECROTIZING MENINGO-ENCEPHALITIS IN CATTLE DUE TO BOVINE HERPESVIRUS \\ IN THE STATE OF MATO GROSSO, BRAZIL
}

\author{
Edson Moleta Colodel ${ }^{2}$ Luciano Nakazato $^{2}$ Rudi Weiblen $^{3}$ Rosane Marine Mello $^{4}$ \\ Roberto Renato Pinheiro da Silva ${ }^{4}$ Marcos de Almeida Souza ${ }^{5}$ José Aguiar de Oliveira Filho ${ }^{6}$ \\ Luizinho Caron $^{7}$
}

RESUMO

Achados epidemiológicos, clínicos, patológicos e microbiológicos de 13 casos de meningoencefalite necrosante pelo Herpesvírus Bovino (BHV), afetando 12 rebanhos bovinos ocorridos no período de março de 1999 a agosto de $2000 \mathrm{em} 11$ municípios do Estado de Mato Grosso são descritos. Onze surtos ocorreram em sistemas de criação extensiva, afetando com maior freqüência animais da raça nelore, e idade média de 24 meses com uma variação de dois a 72 meses. Os principais sinais clínicos descritos foram as alterações neurológicas, sendo relatados salivação profusa, descarga nasal e ocular serosa, depressão profunda, incoordenação, andar a esmo ou em círculo, cegueira, diminuição do tonus lingual, decúbito lateral com movimentos de pedalagem, opistótono e morte. Ausência de alterações foi o relato mais comum durante a necropsia. Em alguns casos, observou-se congestão encefálica difusa, hemorragias submeningeanas multifocais, achatamento de circunvoluções cerebrais e áreas focais de malacias. Os principais achados microscópicos foram meningoencefalite com corpúsculos de inclusão eosinofílicos, intranucleares em astrócitos. As áreas de malacia afetavam principalmente o córtex cerebral. Foi realizado isolamento e caracterização viral em três de um total de sete amostras encaminhadas Em um dos casos, dos que houve isolamento viral, o diagnóstico histopatológico foi de polioencefalomalacia não se observando meningoencefalite $e$ corpúsculos de inclusão.

Palavras-chave: herpesvírus bovino , BHV, meningoencefalite necrosante, encefalite herpética, bovinos, patologia.

\section{SUMMARY}

The epidemiological, clinical, pathological and microbiological aspects of 13 cases of necrotizing meningoencephalitis associated to bovine herpesvirus are described. The disease is described in 12 cattle herds from March 1999 to August 2000 at 11 counties of the State of Mato Grosso, Brazil. The outbreaks were described in cattle raised on farms in which, mostly Zebu breeds were involved. The average age of the cattle affected was 24 months, ranging from two to 72 months old. Neurological manifestations were the main clinical signs noticed. The animals were separated from the herd. The animals showed profuse salivation, serous nasal and ocular discharge, profound depression, incoordination, walking or running in circles, blindness, diminution of tongue tonus, trembling and opistotonus. Most of the cases had no macroscopic alterations. Some cases had diffuse encephalic congestion, multifocal submeningeal hemorragics, flattened cerebral circumvolutions and focal discoloration of the cortex. The main microscopic lesions in the 12 cases were necrotizing meningo-encephalitis with eosinophilic intranuclear inclusion bodies in astrocytes, and cortical malacia. Virus was isolated from three cases submitted from a total of seven examined. One of the cases with virus isolation at the histophatology examination yielded a diagnosis of polioencephalomalacia.

Key words: bovine herpesvirus,. BHV, necrotizing meningoencephalitis, herpetic encephalitis, cattle and pathology.

\footnotetext{
Trabalho realizado com suporte financeiro da FAPEMAT (Fundação de Amparo à Pesquisa do Estado de Mato Grosso).

${ }^{2}$ Médico Veterinário, Professor Assistente do Departamento de Clinica Médica Veterinária da Universidade Federal de Mato Grosso (UFMT), 78000-000, Cuiabá, MT, Brasil. E-mail: moleta@terra.com.br. Autor para correspondência.

${ }^{3}$ Médico Veterinário, Professor Titular, PhD, Departamento de Medicina Veterinária Preventiva, Microbiologia e Parasitologia da Universidade Federal de Santa Maria (UFSM).

${ }^{4}$ Médico Veterinário. Laboratório de Apoio à Saúde Animal, Instituto de Defesa Agropecuária de Mato Grosso, Cuiabá, MT.

${ }^{5}$ Aluno do Curso de Medicina Veterinária da UFMT. Bolsista (PIBIC/CNPq).

${ }^{6}$ Aluno do Curso de Medicina Veterinária da UFMT Bolsista de Extensão/Hospital Veterinário/UFMT

${ }^{7}$ Médico Veterinário, aluno do Programa de Pós-graduação em Medicina Veterinária UFSM.
} 


\section{INTRODUÇÃO}

O herpesvírus bovino tipo 5 (BHV5) é um vírus DNA de cadeia dupla, com envelope, pertencente à família Herpesviridae, subfamília Alphaherpesvirinae, gênero Varicellovirus (ROIZMAN, 1992; FENNER et al., 1993). Inicialmente o herpesvírus bovino (BHV), causador de meningoencefalites, foi classificado como BHV1, idêntico ao causador da Rinotraqueíte Infecciosa Bovina e Vulvovaginite Infecciosa Pustular (FRENCH, 1962), posteriormente denominado BHV tipo 1, subtipo 3 (BHV-1.3) e finalmente, pelas suas características genotípicas distintas, como BHV-5 (ROIZMAN, 1992). Uma característica importante dos BHV é a capacidade de estabelecer latência em gânglios de nervos sensoriais, principalmente trigêmeos (ROCK, 1994) com reativação associada a fatores estressantes.

A reação sorológica cruzada entre os diferentes BHV dificulta levantamentos geográficos de ocorrência do BHV-5 (D'OFFAY et al., 1995). O BHV-5 tem distribuição mundial. No Brasil, meningoencefalites causadas pelo BHV-5 foram relatadas nos Estados do Rio Grande do Sul (RIETCORREA et al., 1989; WEIBLEN et al., 1989, VASCONCELOS et al., 1993, SANCHES et al., 2000), em São Paulo e no Mato Grosso do Sul (SALVADOR et al., 1998). O curso clínico varia entre 1-15 dias e a letalidade está próxima a $100 \%$ (SALVADOR et al., 1998). Os principais sinais clínicos são anorexia, isolamento do rebanho, corrimento nasal e ocular, salivação excessiva, depressão profunda, nistagmo, opistótono, tremores, marcha em círculo, deambular cambaleante, cegueira, paralisia da língua, bruxismo e decúbito com movimento de pedalagem (HILL et al., 1984; SALVADOR $\boldsymbol{e}$ t al., 1998; SANCHES, et al., 2000). $\mathrm{Na}$ necropsia com frequiência não são evidenciadas lesões significativas (SALVADOR et al., 1998). No encéfalo, as principais alterações macroscópicas descritas são áreas de malacia corticais, achatamento de circunvoluções, protrusão cerebelar pelo foramen magno, congestão e hemorragia (RIET-CORREA $\boldsymbol{e t}$ al., 1989; WEIBLEN $\boldsymbol{e t}$ al., 1989; SALVADOR $\boldsymbol{e}$ t al., 1998). Microscopicamente as principais alterações caracterizam-se por meningoencefalite necrosante difusa com áreas de necrose não laminar ocorrendo principalmente na substância cinzenta do córtex cerebral. Podem ser encontradas inclusões intranucleares nos astrócitos e neurônios (RIETCORREA et al., 1989; WEIBLEN et al., 1989; VASCONCELOS et al., 1993; SALVADOR $\boldsymbol{e t}$ al., 1998; SANCHES et al., 2000).
Este trabalho tem por objetivo relatar casos de meningoencefalite associada à infecção por BHV, ocorridos no período de março de 1999 a agosto de 2000 no Estado de Mato Grosso.

\section{MATERIAL E MÉTODOS}

Dados epidemiológicos, sinais clínicos e achados de necropsia dos casos descritos foram obtidos em entrevistas com veterinários ou proprietários que acompanharam os casos clínicos. Foram analisados microscopicamente 196 amostras de encéfalos de bovinos encaminhados por veterinários para o Laboratório de Patologia Veterinária da Universidade Federal de Mato Grosso e para Laboratório de Apoio a Saúde Animal (LASA/INDEA-MT) no período de março de 1999 a agosto de 2000, todas com suspeita clínica de raiva, mas negativas no teste de imunofluorescência. Parte significativa das amostras de encéfalo encaminhadas para esses laboratórios eram recebidas em fragmentos. Nesses casos, procurou-se acondicionar partes do córtex cerebral e tronco encefálico com cerebelo em solução formalina $10 \%$ tamponada e o restante das amostras era congelado à $20^{\circ} \mathrm{C}$ negativos. Encéfalos enviados inteiros tinham a metade longitudinal acondicionada em quantidade suficiente de solução formalina $10 \%$ tamponada por período mínimo de 72 horas. A outra metade longitudinal do encéfalo era mantida congelada à $20^{\circ} \mathrm{C}$. Fragmentos de quatro regiões anatômicas foram sistematicamente processadas para exame histológico. Essas regiões incluíram o córtex cerebral, tálamo, corpos quadrigêmeos e cerebelo com pedúnculos cerebelares e bulbo. Do córtex cerebral, foram analisadas as regiões frontal, parietal e occipital. As amostras foram processadas rotineiramente, incluídas em parafina, cortadas em micrótomo rotativo com $5 \mu \mathrm{m}$ e coradas com hematoxilina e eosina. Os casos selecionados foram numerados de $\mathrm{C} 1$ a $\mathrm{C} 13$ e estão resumidos na tabela 1.

Foram encaminhados para isolamento e caracterização viral, sete casos com estudo microscópico sugestivo de meningoencefalite por BHV ao Setor de Virologia da Universidade Federal de Santa Maria, seguindo-se o seguinte protocolo: Secções do encéfalo frontal e parietal dos animais foram macerados sendo acrescentado Meio Essencial Mínimo (MEM) 5X antibiótico (1:9), sendo o material centrifugado sob refrigeração. $O$ sobrenadante foi coletado e inoculado em monocamadas de células de linhagem Madin Darby Bovine Kidney (MDBK). Após duas horas de adsorção, o inóculo foi retirado e o tapete celular lavado com MEM 5X antibiótico e 
Tabela 1 - Identificação e aspectos epidemiológicos de casos de meningoencefalite necrosante em bovinos no Estado de Mato Grosso no período de março de 1999 a agosto de 2000.

\begin{tabular}{|c|c|c|c|c|c|c|c|c|c|c|}
\hline \multirow[t]{2}{*}{ Caso } & \multirow[t]{2}{*}{ Raça } & \multirow{2}{*}{$\begin{array}{l}\text { Idade } \\
\text { meses }\end{array}$} & \multirow[t]{2}{*}{ Sexo } & \multirow{2}{*}{$\begin{array}{l}\text { Mês/ano de } \\
\text { ocorrência }\end{array}$} & \multicolumn{2}{|c|}{ Total de bovinos } & \multirow{2}{*}{$\begin{array}{l}\text { Número de } \\
\text { doentes }\end{array}$} & \multirow{2}{*}{$\begin{array}{l}\text { Número de } \\
\text { mortos }\end{array}$} & \multirow{2}{*}{$\begin{array}{c}\text { Curso clínico } \\
\text { dias }\end{array}$} & \multirow[t]{2}{*}{ Tipo de criação } \\
\hline & & & & & Propriedade & Lote & & & & \\
\hline $\mathrm{C} 1$ & Nelore & 30 & $\mathrm{~F}$ & $03 / 00$ & 570 & 60 & 08 & 08 & $08 *$ & Extensiva \\
\hline $\mathrm{C} 2$ & Nelore & 02 & $\mathrm{~F}$ & $11 / 99$ & NR & NR & 07 & 07 & 07 & \\
\hline $\mathrm{C} 3$ & Nelore & 02 & M & $11 / 99$ & 1095 & 80 & 03 & 03 & 05 & Extensiva \\
\hline $\mathrm{C} 4$ & $\begin{array}{l}\text { Mestiço } \\
\text { Simental }\end{array}$ & 14 & M & $11 / 99$ & 1095 & 80 & 03 & 03 & $06^{*}$ & $\begin{array}{l}\text { Extensiva/ } \\
\text { recria-engorda }\end{array}$ \\
\hline $\mathrm{C} 5$ & Nelore & 18 & M & $10 / 99$ & 500 & 500 & NR & NR & 05 & Confinamento \\
\hline C6 & Nelore & 18 & $\mathrm{~F}$ & $08 / 00$ & 1560 & 118 & 01 & 01 & 05 & Extensiva \\
\hline $\mathrm{C} 7$ & Nelore & 19 & M & $03 / 00$ & NR & NR & 01 & 01 & NR & Extensiva \\
\hline $\mathrm{C} 8$ & $\begin{array}{l}\text { Mestiço } \\
\text { Simental }\end{array}$ & 72 & $\mathrm{~F}$ & $03 / 00$ & NR & NR & 03 & 03 & 05 & $\begin{array}{c}\text { Extensiva/ } \\
\text { recria-engorda }\end{array}$ \\
\hline C9 & Nelore & 18 & M & $04 / 00$ & 600 & 600 & 07 & 07 & 05 & Extensiva \\
\hline $\mathrm{C} 10$ & Nelore & 24 & M & $05 / 00$ & 900 & 160 & 05 & 05 & 05 & Extensiva \\
\hline $\mathrm{C} 11$ & Nelore & 18 & M & $04 / 00$ & 1300 & 220 & 2 & 02 & 03 & Extensiva \\
\hline $\mathrm{C} 12$ & Nelore & 18 & M & $07 / 00$ & 750 & 750 & 01 & 01 & $03 *$ & Extensiva \\
\hline $\mathrm{C} 13$ & $\begin{array}{l}\text { Nelore } \mathrm{x} \\
\text { Beefalo }\end{array}$ & 15 & M & $08 / 00$ & 1000 & 160 & 01 & 03 & 05 & Extensiva \\
\hline
\end{tabular}

*: sacrificado durante a evolução do quadro clínico. F: fêmea; M: macho;

NR: não relatado

adicionado meio complemento de cultivo. As células foram monitoradas por cinco dias. Foram realizadas três passagens em cultivo celular (CC). Após a inoculação, as células eram monitoradas diariamente para o aparecimento de efeito citopático (ECP). Todas as amostras que apresentaram ECP ou não foram submetidas à técnica de imunofluorescência direta com anticorpos policlonais para BHV-1 marcados com fluoresceína. Foram consideradas positivas as amostras que produziram ECP característico e reagiram à fluoresceína, e negativas as amostras que não produziram ECP após três passagens com cinco dias cada e não reagiram na prova de imunofluorescência.

\section{RESULTADOS}

Os casos de meningoencefalites necrosante associados à infecção por BHV relatados neste trabalho, representaram $6,6 \%$ dos casos que foram caracterizados como negativos para raiva bovina no período de março de 1999 a agosto de 2000. Os casos relatados neste trabalho foram enviados dos seguintes municípios do Estado de Mato Grosso: Cuiabá, Alto Taquari, Arenápolis, Nova Marilândia, Porto dos Gaúchos, Canarana, Rosário do Oeste, Aripuanã, Barra do Garças, Colorado do Leste e Nova Xavantina. Do município de Arenápolis, foram encaminhadas duas amostras (C4 e C5) de um mesmo surto e, de Porto dos Gaúchos, foram encaminhadas duas amostras da mesma propriedade (C11 e C13) em surtos diferentes. Todas as amostras deste estudo foram obtidas de bovinos para produção de carne, sendo dez da raça nelore e três de animais obtidos de cruzamento industrial com animais da raça nelore. Em um dos surtos, os animais estavam em confinamento. Nos casos estudados, nove eram machos, e quatro eram fêmeas. Todos os animais dos surtos aqui relatados que apresentaram sinais clínicos morreram. A evolução clínica variou de três a oito dias. Os principais aspectos epidemiológicos relacionados à ocorrência natural da meningite por BHV no Estado de Mato Grosso estão descritas na tabela 1 .

Os sinais clínicos relatados incluíam inicialmente depressão, anorexia, isolamento do rebanho, corrimento seroso ocular e nasal, sialorréia leve, tremores musculares mais evidentes na cabeça e pescoço, hiperestesia ao toque e ao som, seguido de perda reflexa sensorial principalmente visual sendo descritos também diminuição dos reflexos auditivos e cutâneos. Foram freqüentes os relatos de marcha à esmo com choques em obstáculo ou andar em círculo, trismo, diminuição do tônus lingual, dificuldade para apreensão de alimentos e deglutição de água, ataxia, nistagmo, catatonia, decúbito prolongado com dificuldade para voltar à estação e, finalmente decúbito esternal, decúbito lateral, movimentos de pedalagem, opistótono e morte.

No exame de necropsia a ausência de lesões foi relatada em 5 casos $(\mathrm{C} 1, \mathrm{C} 2, \mathrm{C} 10, \mathrm{C} 11 \mathrm{e}$ C12), em dois casos (C3 e C4) foram achados achatamento das circunvoluções cerebrais, malacia 
cortical caracterizada por áreas multifocais irregulares medindo de 0,5 a $3,0 \mathrm{~cm}$, com coloração amarelada, superfície deprimida e aspecto finamente granular ao corte por vezes associadas a hemorragia e no caso C8 foi relatado, como principal alteração macroscópica hemorragia submeningeana. Nos demais casos não foram feitas descrições dos achados durante a necropsia.

A principal alteração microscópica encontrada no encéfalo dos 13 animais estudados foi meningoencefalite necrosante, aguda, difusa que variou de leve a acentuada em relação ao caso e com a região encefálica. Esta alteração foi caracterizada por acúmulos meningeanos e manguitos perivasculares mononucleares composto principalmente por linfócitos, macrófagos e ocasionais neutrófilos na substância cinzenta do encéfalo, com vasculite e necrose neuronal. Não foram notadas alterações inflamatórias no córtex cerebelar dos casos estudados. Áreas de malacia corticais multifocais foram observadas com freqüência associadas a células Gitter principalmente próximo a áreas superficiais ou submeningeanas por vezes com desaparecimento focal completo da neurópila cortical. Foram notadas também com freqüência gliose multifocal ou difusa com infiltrado mononuclear na neurópila e tumefação de astrócitos. Corpúsculos de inclusão eosinofílicos, intranucleares em astrócitos foram observados principalmente nas áreas com gliose e em astrócitos tumefeitos com núcleo aumentado de volume e com a cromatina formando um halo periférico. Notou-se correlação entre a reação inflamatória e a quantidade de corpúsculos de inclusão. Nos casos C1, C2, C5 e $\mathrm{C} 12$, a resposta inflamatória foi considerada de discreta à leve, sendo encontrado no máximo 1 corpúsculo por campo de observação (40x). Nos casos C4, C7, C10, C11 e C13, apresentaram-se com infiltrado inflamatório de intensidade predominantemente moderado, encontrando-se normalmente dois corpúsculos de inclusão. No caso C3, havia mais de 3 corpúsculos de inclusão por campo microscópico (40x) em algumas áreas de gliose e a reação inflamatória associada ao BHV foi considerada acentuada.

No caso C9, a principal alteração microscópica encontrada no encéfalo foi a necrose cortical cerebral laminar, caracterizada por eosinofilia das camadas corticais superficiais, espongiose da neurópila nas lâminas corticais profundas, aumento do espaço perivascular e perineuronal, eosinofilia e retração de neurônio, tumefação endotelial moderada em vasos corticais e acúmulo leve de células Gitter principalmente nos espaços perivasculares e submeningeano. Não foram observadas lesões inflamatórias em nenhuma das regiões estudadas.

Foram analisados fragmentos de outras vísceras nos casos $\mathrm{C} 3, \mathrm{C} 4$ e $\mathrm{C} 13$, que não apresentaram alterações microscópicas significativas. No cultivo celular, foi caracterizado efeito citopático do BHV em três de oito amostras enviadas, incluindo o caso $\mathrm{C}$ 9, que apresentaram alterações morfológicas de polioencefalomalacia. Os isolados ainda não foram caracterizados pela biologia molecular, no entanto, quando inoculados em coelhos apresentaram um comportamento típico de BHV-5.

\section{DISCUSSÃO}

O diagnóstico da Meningoencefalite por Herpesvírus Bovino, neste estudo, foi baseado nos dados epidemiológicos, sinais clínicos, achados de necropsia, lesões hitopatológicas e isolamento. Os isolados quando inoculados em coelhos tiveram um comportamento típico de BHV-5, ou seja, apresentaram altos índices de mortalidade precedida de sinais nervosos. Os sinais clínicos e achados patológicos em 12 dos 13 casos são semelhantes aqueles descritos na infecção por BHV-5 em bovinos (GARDINER \& NAIRN, 1964; RIETCORREA, 1989; BELKNAP et al., 1994; SALVADOR et al., 1998; SANCHES et al., 2000).

Em todos os casos encaminhados, a suspeita clínica era de raiva bovina. Não havia associação clínica com meningoencefalite por BHV em nenhum dos 13 casos, no entanto foram relatados como sinais clínicos freqüentes, cegueira aparente com choques em obstáculo, bruxismo, andar em círculo e diminuição do tnus lingual, comuns em outros relatos de meningoencefalite por BHV-5 (HILL $\boldsymbol{e}$ t al., 1984, FENNER $\boldsymbol{e}$ t al., 1993; RIETCORREA et al., 1989).

Em quatro casos encaminhados, havia suspeita clínica de polioencefalomalácia (PEM) sendo que a dificuldade clínica na diferenciação de PEM e Meningoencefalite por BHV-5 está mencionada com freqüência na literatura (CARRILLO et al., 1983; GEORGE et al., 1991; SALVADOR et al., 1998). Interessante salientar que foi feito isolamento do BHV no caso C9, porém em exame microscópico, morfologicamente constataram-se alterações que caracterizam a PEM em bovinos, sem que se notassem as lesões inflamatórias similares àquelas encontradas em casos de meningoencefalite por BHV-5. No levantamento epidemiológico do caso $\mathrm{C} 9$, constatouse, na propriedade, que, no surto, foram afetados sete animais, machos, entre 18 e 24 meses. Relatou- 
se ausência de resposta ao uso de medicamento tiamina e antinflamatórios. Esses achados diferem dos relatos de PEM verificadas no Estado de Mato Grosso do Sul onde normalmente há resposta ao tratamento em fases iniciais da doença (PURISCO, 1982; NAKAZATO \& LEMOS, 1998). O isolamento do BHV, neste caso, sem lesões histológicas características da infecção por este vírus, sugere que o vírus estava em estado de latência ainda, ou que estava se replicando em consequiência das lesões de PEM. HUBNER $\boldsymbol{e t} \boldsymbol{a l}$. (1999) sugerem uma relação entre a PEM e a encefalite por BHV-5 sendo esta secundária a PEM em animais latentemente infectados pelo BHV-5. Todavia, no caso $\mathrm{C}$, apenas fragmentos do encéfalo de um dos animais que morreram, foram encaminhados para estudo microscópico, dificultando, assim, o mapeamento das lesões no encéfalo.

A maior ocorrência da enfermidade na raça nelore criados extensivamente, encontrada neste estudo, provavelmente se deva a predomínio de criações a campo de animais desta raça no Estado. Não foi notada distribuição geográfica característica. A principal faixa etária afetada estava com aproximadamente dois anos de idade, variando entre dois a 72 meses semelhante ao encontrado em outros relatos da enfermidade no Brasil (RIET-CORREA $\boldsymbol{e} t$ al., 1989; VASCONCELOS et al., 1993; SALVADOR et al., 1998). A morbidade $\mathrm{e}$ mortalidade, dentro dos lotes afetados, variou entre 0,8 e $22 \%$ no entanto neste estudo não foi possível, na maioria dos casos, estabelecer o manejo adotado para o lote afetado dentro da propriedade.

Foi constatada apenas no caso $\mathrm{C} 4$ introdução regular de bovinos na propriedade divergindo dos relatos de GEORGE (1991) que menciona predisposição à enfermidade quando ocorre introdução de animais portadores em rebanhos susceptíveis, corroborando com os relatos de RIET-CORREA et al. (1989); SALVADOR $\boldsymbol{e t}$ al . (1998).

A ausência de alterações significativas no encéfalo durante a necropsia que foi descrita com freqüência neste trabalho está de acordo com as descrições de literatura (HILL et al., 1984; RIETCORREA et al., 1989; SALVADOR et al., 1998). Áreas de malacia e achatamento de circunvoluções cerebrais são descritos por outros autores (HILL $\boldsymbol{e t}$ al., 1984; SHILD et al., 1994). Protrusão do cerebelo pelo foramen magno, descrito por SALVADOR et $\boldsymbol{a l}$., (1998) e RIET-CORREA \& SCHILD, (1995) não foi observada neste estudo.

Histologicamente menigoencefalite necrosante associada a corpúsculos de inclusão em astrócitos encontrados neste trabalho, são achados significativos relatados por outros autores, em infecção por BHV-5 (GARDINER \& NAIRN, 1964; HILL et al., 1984; WEIBLEN et al., 1989; RIETCORREA et al., 1989; SALVADOR et al., 1998, SANCHES et al., 2000).

Foi possível o isolamento viral apenas dos casos C9, C10, e C11 que ficaram menor tempo sobre congelamento a $20^{\circ} \mathrm{C}$ negativos. Menciona-se que a $-20^{\circ} \mathrm{C}$ o $\mathrm{BHV}$ perde rapidamente a infectividade (FENNER $\boldsymbol{e} \boldsymbol{t} \boldsymbol{a l}$., 1993; ROEHE $\boldsymbol{e t}$ al., 1996). Acredita-se que a extensão territorial do Estado de Mato Grosso e ausência da suspeita clínica tenham contribuído para a conservação inadequada das amostras encaminhadas aos laboratórios envolvidos.

\section{REFERÊNCIAS BIBLIOGRÁFICAS}

BELKNAP, E.B., COLLINS, J.K., AYERS, V.K., et al.. Experimental infection of neonatal calves with neurovirulent bovine herpesvirus type 1.3. Vet Pathol, v.31 p.358-365, 1994.

CARrillo, B.J., AMBRoGi, A., SCHUDEL, A.A., et al. Meningoencephalitis caused by IBR virus in calves in Agentina. Zentralbl Veteriarmed Reihe B, v.30, p.327-332, 1983.

D'OFFAY, J.M., ELY, R.W., BALDWIN, C.A., et al.. Diagnosis of encephalitic bovine herpesvirus type $5(\mathrm{BHV}-5)$ infection in cattle: virus isolation and immunohistochemical detection of antigen in formalin-fixed brain tissues. J Vet Diag Invest, v.7, p.247-251, 1995.

FENNER, F.J., GIBBS, E.P., MURPHY, F.A., et al.. Veterinary virology. 2 ed. New York: Academic, 1993. 659p.

FRENCH, E.L. A specific virus encephalithis in calves: isolation and characterization of the causal agent. Aust Vet J, v.38, p.216-221, 1962.

GARDINER, M.R., NAIRN, M.E. Meningoencephalitis of calves in Western Australia. Aust Vet J, v.40, p.225-228, 1964.

GEORGE, L.W. Understanding the encephalitic form of infectiouns bovine rhinotracheitis. Food Animal Practice, v. March, p.335-337, 1991.

HILL, B.D., HILL, M.W.M., CHUNG, Y.S., et al... Meningoencephalitis in calves due to bovine herpesvirus type 1 infection. Aust Vet J, v.61, p.242-243, 1984.

HUBNER, S.O., RIET-CORREA, F., COSTA, P.B., et al.. Relationship between poliencephalomalacia and encephalitis by bovine herpesvirus-5 in cattle. In: ENCONTRO NACIONAL DE PATOLOGIA VETERINÁRIA, 9, 1999, Belo Horizonte, MG. Anais... Belo Horizonte : UFMG, 1999, p.85.

NAKAZATO, L., LEMOS, R.A. Polioencefalomalacia. In: LEMOS, R.A. Principais enfermidades dos bovinos de corte no Mato Grosso do Sul. Campo Grande : MS/DFA, UFMS, 1998. p.77-108. 
PURISCO, E. Ocorrência de poliencefalomalacia em bovinos no Mato Grosso do Sul. Campo Grande, 1982. Monografia (Especialização em Medicina Veterinária) - Curso de Medicina Veterinária, Universidade Federal de Mato Grosso do Sul, 1982

RIET-CORREA, F., SCHILD, A.L. Doenças diagnosticadas pelo Laboratório Regional de Diagnóstico no ano de 1994 e comentários sobre algumas doenças. Bol Lab Reg Diagnóstico, Pelotas, v.15, p.7-19. 1995

RIET-CORREA, F., VIDOR, T., SCHILD, A.L.., $\boldsymbol{e t}$ al. Meningoencefalite e necrose do córtex cerebral em bovinos causada por herpes vírus bovino-1. Pesq Vet Bras, v.9, p.13$16,1989$.

ROCK D. Latent infection with bovine herpesvirus type-1. Semin Virol, v.5, p.233-240, 1994.

ROEHE, P.M. Diagnóstico de enfermidades víricas de Bovinos. In: ENCONTRO DE LABORATÓRIOS DE DIAGNÓSTICO VETERINÁRIO DO CONE SUL, 1, 1996, Campo Grande, MS. Anais... Campo Grande : UFMS, 1996. p.73-78.
ROIZMAN, B. The family Herpesviridae: an update. Arch Virol, v.123, p.432-445, 1992.

SALVADOR, S.C, LEMOS, R.A.A., RIET-CORREA, F. $\boldsymbol{e}$ t al., Meningoencefalite em bovinos causada por herpesvírus bovino-5 no Mato Grosso do Sul e São Paulo. Pesq Vet Bras, v.18, n.2, p.76-83, 1998.

SANCHES, A.W.D., LANGOHR, I.M., STIGGER, A.L, et al., Doenças do sistema nervoso central em bovinos no Sul do Brasil. Pesq Vet Bras, v.20, n.3, p.113-118, 2000.

SCHILD, A.L., RIET-CORREA, F., FERREIRA, J.L.M., et al. Doenças diagnosticadas pelo Laboratório Regional de Diagnóstico em 1993. Bol Lab Reg Diagnóstico, Pelotas, v.14, p.23-26, 1994

VASCONCELOS , R.O., VARASCHIN, N.S., WOUTERS, F., et al.. Meningoencefalite bovina por herpesvírus. In: ENCONTRO NACIONAL DE PATOLOGIA VETERINÁRIA, 6, 1993, Santa Maria RS. Anais... Santa Maria : UFSM, 1993. p.11.

WEIBLEN, R., BARROS, C.S.L., CANABARRO, T.F., et al. Bovine meningoencephalitis from IBR virus. Vet Rec, v.124, p.666-667, 1989.

Ciência Rural, v. 32, n. 2, 2002. 